\title{
Exercise-induced allergic reactions after achievement of desensitization to cow's milk and wheat
}

\author{
Shohei Kubota ${ }^{1}$, Katsumasa Kkitamura ${ }^{1}$, Teruaki Matsui ${ }^{1}$, Yoshihiro Takasato ${ }^{1}$, Shiro \\ Sugiura $^{1}$, and Komei Ito ${ }^{1}$ \\ ${ }^{1}$ Aichi Children's Health and Medical Center
}

October 20, 2020

\begin{abstract}
Background: We have previously reported that more than half of the patients who achieved desensitization after wheat rush oral immunotherapy (OIT) developed exercise-induced allergic reaction on desensitization (EIARD). However, data on EIARDs after slow OIT are lacking. Therefore, this study aimed to investigate the results of exercise provocation tests (EPTs) in patients after slow OIT for cow's milk and wheat allergies. Methods: This was a retrospective chart review of 87 EPTs in 74 patients. The EPTs were performed in patients who were desensitized to at least $6,600 \mathrm{mg}$ cow's milk protein or 5,200 mg wheat protein with slow OIT and were identified to be at a high risk of EIARDs. EPTs were performed after ingestion of the maximum desensitization dose. The patients' clinical characteristics and symptoms were analyzed. Results: The EPT results were positive for cow's milk in $49 \%(21 / 43)$ of the patients and for wheat in $48 \%(15 / 31)$ of the patients. There was no significant difference in the clinical characteristics between the EIARD-positive and EIARD-negative groups. The specific $\operatorname{IgE}(\mathrm{sIgE})$ levels before OIT and the reduction rates of $\operatorname{sIgE}$ before and after OIT did not correlate with the outcomes of the EPTs. Among the EIARD-positive patients, 13 patients (cow's milk, $\mathrm{n}=7$; wheat, $\mathrm{n}=6$ ) underwent a second EPT, and the EIARD disappeared in 8 patients (cow's milk, $n=4$; wheat, $n=4$ ). Conclusion: EIARDs were observed after slow OIT for cow's milk and wheat. Further research into the predictive factors of EIARDs in these patients is needed to understand its clinical manifestations.
\end{abstract}

\section{Introduction}

Cow's milk $(\mathrm{CM})$ and wheat are the second and third most common causes of childhood food allergies in Japan, respectively. ${ }^{1}$ Although most children with these allergies acquire tolerance spontaneously with age, some do not. ${ }^{2-5}$ While oral immunotherapy (OIT) for CM or wheat in patients who do not acquire tolerance has been shown to be effective in achieving desensitization, ${ }^{6-9}$ exercise after ingestion of the causative antigen can cause immediate allergic symptoms in those children. ${ }^{10-14}$ Manabe et al. suggested two types of exercise-induced allergic symptoms: food-dependent exercise-induced anaphylaxis (FDEIA or FEIAn) ${ }^{15}$ and desensitization status and exercise-induced anaphylaxis. ${ }^{10,16}$

We have previously reported on 14 cases of exercise-induced allergic reactions among 20 patients who were desensitized to $5,200 \mathrm{mg}$ wheat protein after rush OIT (ROIT). ${ }^{11}$ We designated this status as "exerciseinduced allergic reaction on desensitization" (EIARD). There are also several case reports of EIARD after both slow OIT and ROIT. ${ }^{11,12-14}$ However, there are no case series or case control studies of EIARD after the implementation of slow OIT. Therefore, this study aimed to analyze the results of exercise provocation tests (EPTs) for the diagnosis of EIARD after slow OIT and identify the factors associated with EIARD.

\section{Methods}

\section{Study design and population}


This was a retrospective study of patients who achieved desensitization to 6,600 $\mathrm{mg}$ CM protein or 5,200 mg wheat protein after slow OIT and who underwent EPTs between March 2012 and December 2019. All EPTs were performed at the Aichi Children's Health and Medical Center. EPTs with acetylsalicylic acid used as a cofactor ${ }^{17}$ were excluded from the analysis.

\section{Oral immunotherapy}

The initial dose of slow OIT was based on the total doses and severity of allergic symptoms in oral food challenges ${ }^{18,19}$ (e.g., one-tenth of the symptom-provoked threshold dose). For patients whose symptomprovoked threshold dose was $>66 \mathrm{mg}$ CM protein or $52 \mathrm{mg}$ wheat protein, the dose was increased by $10-20 \%$ for every 5-10 ingestions without symptoms. The dose was increased more slowly for the patients whose threshold was $<66 \mathrm{mg} \mathrm{CM}$ protein or $52 \mathrm{mg}$ wheat protein, as previously reported. ${ }^{18}$ All patients were instructed to avoid exercising and bathing 1 hour before and 2 hours after taking the dose to minimize the risk of exercise-induced symptoms. After achieving desensitization with the full dose (6,600 mg CM protein or 5,200 mg wheat protein $)^{1}$, all patients were instructed to exercise after allergen consumption at home with the aim of ensuring the safe consumption of school meals. Patients at high risk (e.g., those who had experienced allergic symptoms due to unintended exercise during OIT, had experienced anaphylaxis during OIT without exercise, or had induced allergic symptoms, suspected to have been caused by exercise after ingestion at home) underwent EPTs in the hospital.

\section{Exercise provocation tests}

Patients ingested the maximum desensitization dose and underwent either a free running or treadmill ergonometric stress test or a stepping exercise test after 30 minutes. The EPT was performed for at least 15 minutes, with a target heart rate of $>180$ beats/minute. Patients with negative EPT results were instructed to exercise after ingestion at home to confirm the negative result. Patients with positive EPT results underwent repeat EPTs after a period of time (usually about 2 years) according to the physicians' and families' discretions to check for remission.

\section{Risk factors of EIARD}

The following clinical information was collected as potential factors associated with EIARD: age at the start of OIT and at EPT; history of other allergic diseases; average pace of increasing the amount of antigen during OIT (defined as the difference between the full dose and the starting dose, divided by the duration of OIT); and specific IgE (sIgE) titer (milk and casein, or wheat and $\omega-5$ gliadin) before starting OIT and within 1 year before the EPT (after OIT). sIgE levels were detected using ImmunoCAP ${ }^{\circledR}$ (Thermo Fisher Scientific, Uppsala, Sweden). A level of [?]0.34 kUA/L was fixed at $0.34 \mathrm{kUA} / \mathrm{L}$, indicating no sensitization. Levels $>100 \mathrm{kUA} / \mathrm{L}$ were fixed at $100 \mathrm{kUA} / \mathrm{L}$.

\section{Statistical analysis}

All statistical analyses were conducted using R-3.6.0 program (R Development Core Team: R: A language and environment for statistical computing. R Foundation for Statistical Computing, Vienna, Austria). Between-group comparisons were performed using the Mann-Whitney $\mathrm{U}$ test or Wilcoxon rank sum test for continuous variables and using the Fisher's exact test for categorical variables. $P$ values of $<0.05$ were considered statistically significant.

\section{Ethical Considerations}

This study was conducted in accordance with the Declaration of Helsinki and was approved by the institutional ethical board of Aichi Children's Health and Medical Center (No. 2017001). All EPTs were performed after obtaining written informed consent of the parents and informed consent of the patients, including the permission to use the results for this retrospective research. Slow OIT was also conducted after obtaining approval from the ethical board (No. 2012043 and 201427) and informed consent of the parents and patients.

\section{Results}




\section{Patient and oral immunotherapy characteristics}

Baseline patient characteristics are reported in Table 1. For patients with CM allergy, the initial OIT dose was > $66 \mathrm{mg}$ CM protein in $26(60 \%)$ patients; <66 $\mathrm{mg}$ in $15(35 \%)$ patients; and unknown in two patients. For patients with wheat allergy, the initial OIT dose was $>52 \mathrm{mg}$ wheat protein in 11 (35\%) patients; $<52$ $\mathrm{mg}$ in $16(52 \%)$ patients; and unknown in four patients. In total, four $(9 \%) \mathrm{CM}$ allergy patients and five $(16 \%)$ wheat allergy patients experienced anaphylaxis by the programed intake of the allergens during OIT without exercise. Of them, one patient with a CM allergy required an adrenaline injection. Among the CM allergy patients, $5 \%$ achieved desensitization with a full dose by 1 year, $35 \%$ by 2 years, and $60 \%$ by 3 years after the start of OIT. Among the wheat allergy patients, $17 \%$ achieved desensitization with a full dose by 1 year, $42 \%$ by 2 years, and $79 \%$ by 3 years after the start of OIT. The rest took more than 3 years to reach the full dose.

\section{Exercise provocation tests}

There were $20 \mathrm{CM}$ allergy patients who developed allergic symptoms at the first EPT (Figure 1). One CM-EPT-negative patient experienced a convincing event of EIARD at home. Therefore, 21 patients (49\%) were diagnosed as EIARD-positive, and 22 patients were EIARD-negative for CM. Table S1 shows the characteristics and the results of EPTs of the 21 CM EIARD-positive patients. There were eight (38\%) patients who were administered antihistamines and eight (38\%) patients who were administered $\beta 2$ stimulants, of whom one received both antihistamines and $\beta 2$ stimulants at the first EPT. Two patients received an intramuscular injection of adrenaline for anaphylactic shock (cases 17 and 19). Of these 21 CM EIARD-positive patients, seven (33\%) underwent a second EPT, of whom four tested negative (Figure 1). The second EPT was performed within a median of 1.5 (range: 0.9-3.4) years after the first EPT.

Among the 31 patients with a wheat allergy, 14 patients were EPT-positive (Figure 2). One wheat-EPTnegative patient experienced EIARD at home. Thus, 15 patients (48\%) were diagnosed to be EIARD-positive and 16 patients were EIARD-negative for wheat. Table S2 shows the characteristics of the 15 wheat EIARDpositive patients. There were seven $(47 \%)$ patients who were administered antihistamines and six $(40 \%)$ patients who were administered $\beta 2$ stimulants, of whom five received both antihistamines and $\beta 2$ stimulants at the first EPT. None of the patients received adrenaline. In total, six (40\%) patients who tested positive during the first EPT underwent a second EPT after a median of 2.1 (range: 0.4-5.9) years. Of these, four tested negative (Figure 2).

\section{Risk factors of EIARDs and specific IgE levels}

There was no significant difference in the characteristics and median age of starting OIT between the EIARDpositive and EIARD-negative groups (Table 2). There was also no significant difference in the average pace of increasing the amount of antigen in the OIT between the two groups for CM $(P=0.52)$ and wheat $(P$ $=0.053$ ) allergies.

With respect to the sIgE levels, there was no significant difference between the EIARD-positive and EIARDnegative groups before the start of OIT (CM: $P=0.51$, casein: $P=0.96$, wheat: $P=0.93$, $\omega-5$ gliadin: $P$ $=0.23$; Table 2). There was also no significant difference in [?]food allergen-sIgE calculated using the formula ([difference between sIgE before OIT and sIgE after OIT]/sIgE before OIT) between the groups. In both groups, the sIgE levels of CM, casein, wheat, and $\omega-5$ gliadin were lower after OIT than before OIT $(P$ $<0.001$ for all comparisons, Figure 3). The sIgE titer after OIT was not tested in one of the two patients who developed an anaphylactic shock in response to CM during the EPT (case 17) and in another patient who had CM-sIgE levels of $0.43 \mathrm{kUA} / \mathrm{L}$ and casein-sIgE levels of $0.49 \mathrm{kUA} / \mathrm{L}$ (case 19). Eight patients in the wheat EIARD-positive group showed negative sIgE to $\omega-5$ gliadin measured after OIT (Table 2).

\section{Discussion}

Evidence on EIARD after slow OIT is scarce. Herein, EIARDs were observed in some patients with IgEmediated wheat or CM allergy after slow OIT. Although we could not identify the factors associated with 
developing EIARDs, to the best of our knowledge, this is the first case-control study of EIARD after slow OIT.

FDEIA is another type of food allergy induced by exercise after ingestion of the causative antigen despite there being no immediate history of allergy with the causal food in the past. Although wheat is a major causative antigen of FDEIA, CM as a causative agent is rare. ${ }^{20}$ EIARDs are considered to be the residual symptoms of immediate food allergies at the time of incomplete desensitization. This indicates that EIARDs and FDEIAs have completely different pathologies.

Although the pathophysiology of EIARDs is currently unclear, exercise reduces the symptom-provoked threshold by $45 \%$ in patients with a peanut allergy. ${ }^{21}$ Thus, even patients who become desensitized by more than a full dose may still develop allergic symptoms by the lowering of the symptom-provoking threshold with exercise. Increasing the amount of absorbed antigen with exercise might affect this phenomenon. ${ }^{22}$

Exercise should be avoided for two hours after ingestion of the antigen during OIT, including during the maintenance phase, to reduce the risk of inducing allergic symptoms. ${ }^{23}$ Therefore, evaluation of the absence of EIARDs is important to ensure safety during daily meals, including school meals. The definitive evaluation using an EPT is desirable in those patients who have an unstable occurrence of allergic symptoms during OIT, or in those who have a suspected episode of EIARD after OIT. However, one negative EPT is not enough to exclude the possibility of having EIARD. The absence of allergic symptoms should be reconfirmed at home. Although it is not easy to completely exclude EIARD, this procedure is important to avoid unnecessary restrictions on combining consumption with exercise. ${ }^{24}$ In addition, once the presence of EIARD is diagnosed, subsequent EPTs may be worthwhile to evaluate the cessation of EIARD.

With respect to risk factors of EIARDs, we were unable to identify predictive factors among patients who developed desensitization. In terms of antibody titers, in most cases, the post-OIT sIgE level was lower than the pre-OIT level. This may have been due to the effect of the OIT. ${ }^{25}$ However, there were no significant differences in either CM or wheat sIgE before OIT, nor any changes in the values before or after OIT between the EIARD-positive and EIARD-negative groups. Moreover, there were some cases of negative $\omega-5$ gliadin sIgE levels after OIT among patients in the wheat EIARD-positive group. One patient in the CM EIARDpositive group was also negative for both CM and casein SIgE measured after the OIT. In previously reported cases of EIARDs, after slow OIT, casein and $\omega-5$ gliadin sIgE levels measured immediately before OIT were negative. ${ }^{12,14}$ These findings support the conclusion that blood antibody titers are not predictive of EIARDs.

Sustained unresponsiveness (SU) has been identified as an indicator of the therapeutic effect of OIT. ${ }^{8}$ However, the relationship between SU and EIARDs has not been evaluated in the present study. We instructed the patients to introduce CM and wheat products in their daily diet, preferably to enable routine consumption rather than to evaluate the achievement of SU. One institution in Japan reported that $41 \%$ of patients who were confirmed to have 2 weeks of SU after OIT experienced allergic symptoms including anaphylaxis within 4 years of confirmation of SU. ${ }^{26}$ Importantly, the most common trigger of the symptoms was exercise. Therefore, even patients diagnosed with SU may still be at risk of EIARDs.

This study found that EIARDs may remain for several years after slow OIT, in patients who continued to consume daily amounts of antigen. Thus, EIARDs are an indicator of a state of desensitization that has not yet reached tolerance. Considering the patient's daily life after OIT, the use of EIARDs as an indicator of the effectiveness of OITs, in addition to SU, should be expanded.

We did not routinely examine EPTs in patients who developed uneventful desensitization to the full antigen dose accompanied by physical exercise. At our institution, approximately 30 patients per year achieve desensitization to the full dose of CM and wheat without developing EIARD. This suggested that roughly 5-10\% of the patients who achieved desensitization after slow OIT developed EIARD.

A nationwide survey in Japan found that OITs were performed more frequently in 2015 than in $2011 .^{27}$ Consequently, occurrence of allergic symptoms during exercise in desensitized children has become a significant issue at school. Physicians are expected to evaluate the possibility of an EIARD before permitting patients 
to consume the target food in their daily meals, especially at school. Currently, EPT is the only, if not the best, procedure to determine the appearance of an EIARD. However, performing an EPT requires big medical resources. Furthermore, it is burdensome for the patients and is accompanied by the risk of anaphylaxis. Further studies are needed to identify the risk factors of EIARD and develop alternative diagnostic methods.

This study has some limitations. First, owing to the retrospective nature of the study, we could not calculate the actual frequency of EIARD occurrence after OIT. Second, we categorized into EIARD-positive and negative, only those patients who had undergone an EPT because they were identified to have a high risk of developing EIARDs. The risk factors of EIARD should be assessed in a prospective manner, in desensitized patients who are not suspected of developing an EIARD. Further prospective studies are warranted to determine the predictive factors and alternative diagnostic methods of EIARDs.

In conclusion, EIARDs were observed after slow OIT for CM and wheat. EIARD influences the daily meals of even those patients, who are desensitized to the full dose of the allergen. Evaluation of EIARDs after OIT should be important in the clinical management of patients with food allergies. Further research into the predictive factors of EIARDs is needed to understand its clinical manifestations.

\section{Author contributions}

Shohei Kubota designed the paper, processed the data, performed the analysis, and drafted the manuscript. Katsumasa Kitamura, Teruaki Matsui, and Yoshihiro Takasato contributed to the conception and interpretation of the study and reviewed the paper. Shiro Sugiura and Komei Ito conceptualized the study, analyzed and interpreted the data, and supervised the findings of this work. All authors discussed the results and contributed to the final manuscript.

\section{Acknowledgements}

We appreciate the help of our colleagues in Aichi Children's Health and Medical Center. We would also like to thank Editage (www.editage.com) for English language editing.

\section{Impact statement}

This is the first case series of exercise-induced allergic reaction on desensitization (EIARD) after the implementation of slow oral immunotherapy (OIT) for wheat and cow's milk. Although this study was conducted in a retrospective manner, the strength of this study is that the diagnosis of EIARD was based on the exercise provocation tests (EPTs). We found that EIARDs occur not only after rush OIT for wheat ${ }^{11}$, but also after slow OIT for cow's milk and wheat.

\section{References}

1) Ebisawa M, Ito K, Fujisawa T. Japanese guidelines for food allergy 2017. Allergol Int 2017;66:248-264.

2) Elizur A, Rajuan N, Goldberg MR, Leshno M, Cohen A, Katz Y. Natural course and risk factors for persistence of IgE-mediated cow's milk allergy. J Pediatr 2012;161:482-487.

3) Skripak JM, Matsui EC, Mudd K, Wood RA. The natural history of IgE-mediated cow's milk allergy. $J$ Allergy Clin Immunol2007;120:1172-1177.

4) Keet CA, Matsui EC, Dhillon G, Lenehan P, Paterakis M, Wood RA. The natural history of wheat allergy. Ann Allergy Asthma Immunol2009;102:410-415.

5) Kotaniemi-Syrjänen A, Palosuo K, Jartti T, Kuitunen M, Pelkonen AS, Mäkelä MJ. The prognosis of wheat hypersensitivity in children.Pediatr Allergy Immunol 2010;21:e421-e428.

6) Longo G, Barbi E, Berti I, et al. Specific oral tolerance induction in children with very severe cow's milk-induced reactions. J Allergy Clin Immunol 2008;121:343-347.

7) Kaneko H, Teramoto T, Kondo M, et al. Efficacy of the slow dose-up method for specific oral tolerance induction in children with cow's milk allergy: comparison with reported protocols. J Investig Allergol Clin 
Immnunol 2010;20:538-539.

8) Sato S, Utsunomiya T, Imai T, et al. Wheat oral immunotherapy for wheat-induced anaphylaxis. $J$ Allergy Clin Immunol2015;136:1131-1133.e7.

9) Rodriguz del Rio P, Diaz-Perales A, Sanchez-Garcia S, et al. Oral immunotherapy in children with IgEmediated wheat allergy: outcome and molecular changes. J Investig Allergol Clin Immunol2014;24:240-248.

10) Manabe T, Oku N, Aihara Y. Food-dependent exercise-induced anaphylaxis among junior high school students: a 14-year epidemiological comparison. Allergol Int 2015;64:285-286.

11) Furuta T, Tanaka K, Tagami K, et al. Exercise-induced allergic reactions on desensitization to wheat after rush oral immunotherapy.Allergy 2020;75:1414-1422.

12) Caminiti L, Passalacqua G, Vita D, Ruggeri P, Barberio G, Panjo GB. Food-exercise-induced anaphylaxis in a boy successfully desensitized to cow milk. Allergy 2007;62:335-336.

13) Calvani M, Sopo SM. Exercise-induced anaphylaxis caused by wheat during specific oral tolerance induction. Ann Allergy Asthma Immunol 2007;98:98-99.

14) Kusunoki T, Mukaida K, Hayashi A, et al. A case of wheat-dependent exercise-induced anaphylaxis after specific oral immunotherapy. J Investig Allergol Clin Immunol 2014;24:358-359.

15) Kidd JM 3rd, Cohen SH, Sosman AJ, Fink JN. Food-dependent exercise-induced anaphylaxis. J Allergy Clin Immunol1983;71:407-411.

16) Manabe T, Oku N, Aihara Y. Food-dependent exercise-induced anaphylaxis in Japanese elementary school children. Pediatr Int2018;60:329-333.

17) Matsuo H, Morimoto K, Akaki T, et al. Exercise and aspirin increase levels of circulating gliadin peptides in patients with wheat-dependent exercise-induced anaphylaxis. Clin Exp Allergy 2005;35:461-466.

18) Sugiura S, Kitamura K, Makino A, et al. Slow low-dose oral immunotherapy: threshold and immunological change. Allergol Int2020;69:601-609.

19) Ito K. Diagnosis of food allergies: the impact of oral food challenge testing. Asia Pac Allergy 2013;3:59-69.

20) Asaumi T, Yanagida N, Sato S, Shukuya A, Nishino M, Ebisawa M. Provocation tests for the diagnosis of food-dependent exercise-induced anaphylaxis. Pediatr Allergy Immunol 2016;27:44-49.

21) Dua S, Ruiz-Garcia M, Bond S, et al. Effect of sleep deprivation and exercise on reaction threshold in adults with peanut allergy: A randomized controlled study. J Allergy Clin Immunol2019;144:1584-1594.e2.

22) Pals KL, Chang RT, Ryan AJ, Gisolfi CV. Effect of running intensity on intestinal permeability. J Appl Physiol 1997;82:571-576.

23) Arasi S, Caminiti L, Crisafulli G, et al. The safety of oral immunotherapy for food allergy during maintenance phase: Effect of counselling on adverse reactions. World Allergy Organ J2019;12:1-3.

24) Rigbi NE, Goldberg MR, Levy MB, Nachshon L, Golobov K, Elizur A. Changes in patient quality of life during oral immunotherapy for food allergy. Allergy 2017;72:1883-1890.

25) Longo G, Barbi E, Berti I, et al. Specific oral tolerance induction in children with very severe cow's milk-induced reactions. J Allergy Clin Immunol 2008;121:343-347.

26) Manabe T, Sato S, Yanagida N, et al. Long-term outcomes after sustained unresponsiveness in patients who underwent oral immunotherapy for egg, cow's milk, or wheat allergy. Allergol Int2019;68:527-528.

27) Sato S, Sugizaki C, Yanagida N, et al. Nationwide questionnaire-based survey of oral immunotherapy in Japan.Allergol Int 2018;67:399-404.

Table 1. Baseline patient characteristics 


\begin{tabular}{lll}
\hline & Cow's milk allergy patients & Wheat allergy patients \\
\hline & $(\mathrm{n}=43)$ & $(\mathrm{n}=31)$ \\
Male sex, n (\%) & $34(79 \%)$ & $28(90 \%)$ \\
History of atopic dermatitis, n (\%) & $31(72 \%)$ & $23(74 \%)$ \\
History of bronchial asthma, n (\%) & $22(51 \%)$ & $13(42 \%)$ \\
History of allergic rhinitis, n (\%) & $34(79 \%)$ & $21(68 \%)$ \\
History of anaphylaxis, n (\%) & $22(56 \%)$ & $22(71 \%)$ \\
Age at starting slow OIT (years) & $5.6(1.6-11.5)$ & $5.6(1.1-13.8)$ \\
OIT initial dose, n (\%) & & $? \dot{.} ?$ \\
66 mg cow's milk protein or [?]52 mg wheat protein & $26(60 \%)$ & $11(35 \%)$ \\
$<66$ mg cow's milk or <52 mg wheat protein & $15(35 \%)$ & $16(52 \%)$ \\
Unknown & $2(5 \%)$ & $4(13 \%)$ \\
Duration from starting OIT to the full dose (years) & $2.6(0.3-6.9)$ & $2.2(0.7-3.8)$ \\
Duration from starting OIT to the EPT (years) & $4.1(0.7-10.4)$ & $3.6(1.7-9.7)$ \\
sIgE (crude) before OIT (kUA/L) & $20(1.33-100)$ & $22.2(4-100)$ \\
sIgE (component) before OIT (kUA/L) & $17.3(1.36-100)$ & $0.9(0.34-16.7)$ \\
\hline
\end{tabular}

Values are presented as the number (\%) or median (range).

sIgE (crude), specific immunoglobin E titer to cow's milk, and wheat

sIgE (component), specific immunoglobin E titer to casein (cow's milk), and $\omega-5$ gliadin (wheat).

Levels of [?]100 kUA/L and [?]0.34 kUA/L were set to $100 \mathrm{kUA} / \mathrm{L}$ and $0.34 \mathrm{kUA} / \mathrm{L}$, respectively.

The full dose was set to $6600 \mathrm{mg}$ cow's milk protein and $5200 \mathrm{mg}$ wheat protein.

Abbreviations: EPT: exercise-provocation test, OIT: oral immunotherapy

Table 2. Factors associated with EIARD positivity

\begin{tabular}{|c|c|c|c|c|c|c|}
\hline & Cow's milk & Cow's milk & Cow's milk & Wheat & Wheat & Wheat \\
\hline $\begin{array}{l}\text { Age at EPT } \\
\text { (years) }\end{array}$ & $\begin{array}{l}\text { EIARD }+ \\
10.2 \\
(6.5-15.7)\end{array}$ & $\begin{array}{l}\text { EIARD- } \\
10.6 \\
(6.2-14.4)\end{array}$ & $\begin{array}{l}p \\
0.52\end{array}$ & $\begin{array}{l}\text { EIARD+ } \\
9.4 \\
(5.5-16)\end{array}$ & $\begin{array}{l}\text { EIARD- } \\
9.3 \\
(6.3-13.4)\end{array}$ & $\begin{array}{l}p \\
0.94\end{array}$ \\
\hline $\begin{array}{l}\text { History of } \\
\text { atopic } \\
\text { dermatitis, n } \\
(\%)\end{array}$ & $15(71 \%)$ & $16(73 \%)$ & 1 & $9(60 \%)$ & $14(88 \%)$ & 0.11 \\
\hline $\begin{array}{l}\text { History of } \\
\text { bronchial } \\
\text { asthma, n } \\
(\%)\end{array}$ & $12(57 \%)$ & $10(45 \%)$ & 0.55 & $7(47 \%)$ & $6(38 \%)$ & 0.72 \\
\hline $\begin{array}{l}\text { History of } \\
\text { allergic } \\
\text { rhinitis, n } \\
(\%)\end{array}$ & $17(81 \%)$ & $17(77 \%)$ & 1 & $12(80 \%)$ & $9(56 \%)$ & 0.25 \\
\hline $\begin{array}{l}\text { Age at } \\
\text { starting slow } \\
\text { OIT (years) }\end{array}$ & 5.1 & 5.9 & 0.95 & 6 & 5.2 & 0.4 \\
\hline & $(2.2-11.5)$ & $(1.6-10.8)$ & & $(1.7-13.8)$ & $(1.1-10.6)$ & \\
\hline
\end{tabular}




\begin{tabular}{|c|c|c|c|c|c|c|}
\hline & Cow's milk & Cow's milk & Cow's milk & Wheat & Wheat & Wheat \\
\hline $\begin{array}{l}\text { OIT initial } \\
\text { dose (mg of } \\
\text { cow's milk or } \\
\text { wheat protein) }\end{array}$ & $(3-1650)$ & $(7-330)$ & 0.713 & $(2-260)$ & $(5-260)$ & 0.51 \\
\hline $\begin{array}{l}\text { OIT initial } \\
\text { dose, } n\end{array}$ & & & & & & \\
\hline $\begin{array}{l}{[?] 66 \mathrm{mg}} \\
\text { cow's milk } \\
\text { protein or } \\
{[?] 52 \mathrm{mg}} \\
\text { wheat } \\
\text { protein }\end{array}$ & 16 & 10 & 0.11 & 6 & 5 & 1 \\
\hline $\begin{array}{l}<66 \mathrm{mg} \\
\text { cow's milk } \\
\text { protein or } \\
<52 \mathrm{mg} \\
\text { wheat } \\
\text { protein }\end{array}$ & 5 & 10 & & 8 & 8 & \\
\hline $\begin{array}{l}\text { Duration } \\
\text { from } \\
\text { starting OIT } \\
\text { to }\end{array}$ & 2.7 & 2.6 & 0.49 & 2 & 2.9 & 0.053 \\
\hline $\begin{array}{l}\text { the full dose } \\
\text { (years) }\end{array}$ & $(0.6-6.9)$ & $(0.3-5.1)$ & & $(0.7-7)$ & $(1.1-6)$ & \\
\hline $\begin{array}{l}\text { Average } \\
\text { pace of } \\
\text { increasing } \\
\text { intake } \\
\text { (mg/years) }\end{array}$ & 2422 & 2570 & 0.52 & 3349 & 2314 & 0.053 \\
\hline $\begin{array}{l}\text { Duration } \\
\text { from } \\
\text { starting OIT } \\
\text { to }\end{array}$ & 4.2 & 4.4 & 0.83 & 3.4 & 4.2 & 0.41 \\
\hline $\begin{array}{l}\text { the EPT } \\
\text { (years) }\end{array}$ & $(0.7-10.4)$ & $(0.7-8.8)$ & & $(1.9-7.7)$ & $(1.7-9.7)$ & \\
\hline sIgE (crude) & 15.7 & 20.2 & 0.51 & 21.9 & 17.3 & 0.93 \\
\hline \multirow{3}{*}{$\begin{array}{l}\text { sIgE } \\
\text { (component) } \\
\text { before OIT } \\
(\mathrm{kUA} / \mathrm{L})\end{array}$} & $(3.22-100)$ & $(1.33-100)$ & & $(1.36-100)$ & $(4.22-100)$ & \\
\hline & 14 & 22.4 & 0.96 & 3.22 & 0.54 & 0.23 \\
\hline & $(4-100)$ & $(5.47-100)$ & & $(0.34-16.7)$ & $(0.34-5.95)$ & \\
\hline
\end{tabular}

Values are presented as the number (\%) or median (range).

Blood sampling occurred within 1 year of commencing consumption. 
sIgE (crude), specific immunoglobin E titer to cow's milk, and wheat sIgE (component), specific immunoglobin $\mathrm{E}$ titer to casein (cow's milk), and $\omega-5$ gliadin (wheat)

[?] crude-sIgE and [?]component-sIgE were defined as the rate of change between sIgE before slow OIT and the first exercise.

Levels of 100 [?]kUA/L and [?]0.34 kUA/L were set to $100 \mathrm{kUA} / \mathrm{L}$ and $0.34 \mathrm{kUA} / \mathrm{L}$, respectively.

The average pace of increasing intake was defined as the full dose minus the initial dose, divided by the number years of consumption

The full dose was set to $6600 \mathrm{mg}$ cow's milk protein and $5200 \mathrm{mg}$ wheat protein.

Continuous and categorical variables were analyzed using the Mann-Whitney $U$ test and the Fisher's exact test, respectively.

Abbreviations: EIARD: exercise-induced allergic reaction on desensitization, EPT: exercise-provocation test, OIT: oral immunotherapy

\section{Figure legends}

Figure 1. Flowchart of the exercise provocation test for cow's milk.

After slow oral immunotherapy (OIT) to cow's milk, 43 patients underwent the first exercise provocation test (EPT). Of them, 20 patients' results were negative. One negative patient experienced a convincing event of exercise-induced allergic reaction to desensitization (EIARD) at home. Ultimately, 21 and 22 patients were diagnosed as EIARD-positive and EIARD-negative, respectively. Seven patients underwent a second EPT, of which four tested negative.

Figure 2. Flowchart of the exercise provocation test for wheat.

After slow oral immunotherapy (OIT) to wheat, 31 patients underwent the first exercise provocation test (EPT). Of them, 14 patients' results were negative. One negative patient experienced a convincing event of exercise-induced allergic reaction on desensitization (EIARD) at home. Finally, 15 and 16 patients were diagnosed as EIARD-positive and EIARD-negative, respectively. Six patients underwent a second EPT, and four of them tested negative.

Figure 3. Time course of the specific IgE detection in response to cow's milk, wheat, and each component

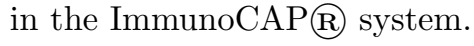

In the EIARD-positive and EIARD-negative groups, sIgE levels of cow's milk, casein, wheat, and $\omega-5$ gliadin measured after slow oral immunotherapy (OIT) were lower than those measured before the start of OIT.

\section{Appendices: NA}



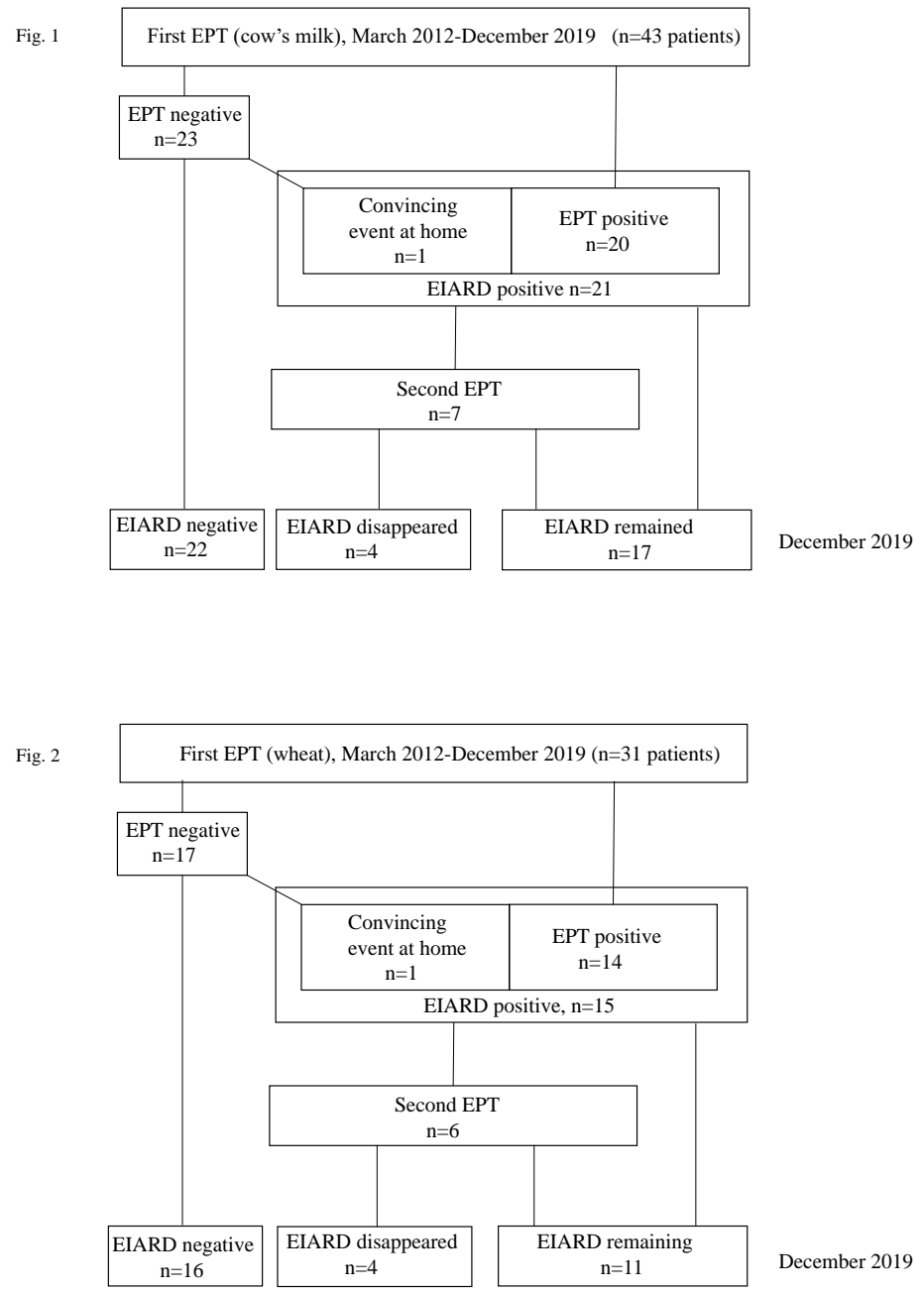

December 2019

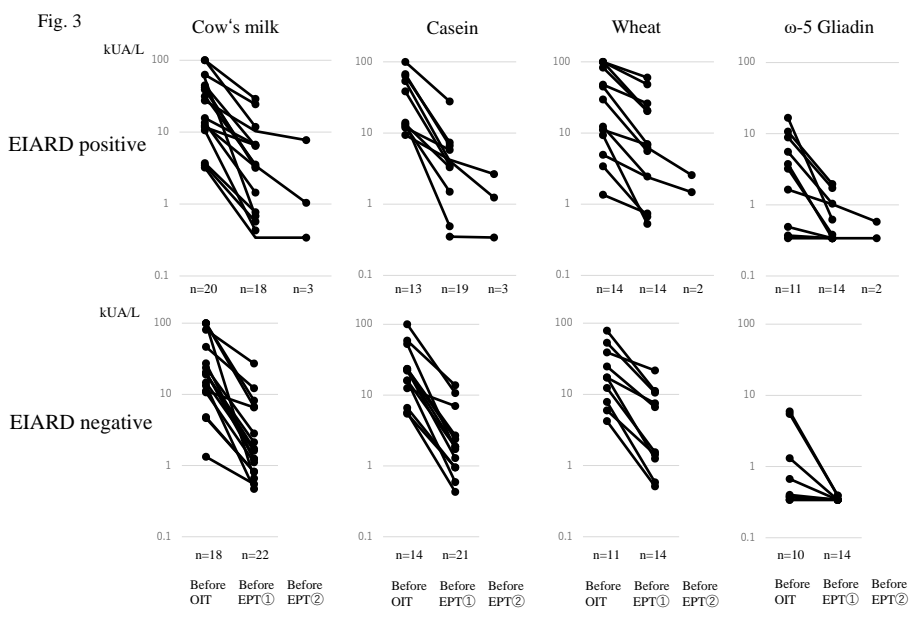

